\title{
Characteristics of carbonaceous aerosols and their relationship with emission sources
}

\author{
H. Minoura ${ }^{1,2}$, K. Takahashi ${ }^{3}$, T. Morikawa ${ }^{4}$, \\ A. Mizohata ${ }^{5}$ \& K. Sakamoto ${ }^{6,7}$ \\ ${ }^{1}$ Toyota Motor Engineering \& Manufacturing North America, USA \\ ${ }^{2}$ Toyota Central R\&D Labs. Inc., Japan \\ ${ }^{3}$ Japan Environmental Sanitation Center, Japan \\ ${ }^{4}$ Japan Automobile Research Institute, Japan \\ ${ }^{5}$ Radiation Research Center, Osaka Prefecture University, Japan \\ ${ }^{6}$ Center for Environmental Science and Technology, \\ Saitama University, Japan \\ ${ }^{7}$ Center for Environmental Science in Saitama, Japan
}

\begin{abstract}
Due to enforcing vehicle emission reduction requirements in Japan, particulate matter (PM) concentration, especially the elemental carbon (EC) concentration in roadside atmosphere, significantly decreased during the last decade. However, in spite of vehicle emission reductions, recent EC concentrations in the overall ambient air did not show a clear decrease. To achieve the $\mathrm{PM}_{2.5}$ environmental standard, measurements based on emission source contribution was desired. However, source apportionment of carbonaceous aerosol was ambiguous because chemical components are complicated, and the components change through photochemical reaction.

The goal of this study was to determine source apportionment for carbonaceous aerosols. Examination of $\mathrm{PM}_{2.5}$ was performed in south Kanto including Tokyo in the summer of 2008 and the winter of 2009. Emissions from the industrial area around Tokyo Bay and the agricultural northern area showed PM transport and accumulation due to a seasonal prevailing wind. The characteristics of carbonaceous aerosol were obtained using carbon profile analysis and carbon isotope analysis.

Soot-EC was found as a substance with fossil fuel origin which did not contain biomass combustion matter. Since soot-EC is stable, there was no
\end{abstract}


observed difference by site and a uniform concentration was observed in winter. It became apparent from the carbon isotope analysis using ${ }^{14} \mathrm{C}$ that carbon from biomass origin comprised $29 \%$ of the total carbon in the summer, and $48 \%$ of the total carbon in winter. This was found at all sites, even at Kudan in central Tokyo. The biomass contribution measured for this study did not show a significant difference from the 2004 measured results. It is not understood why the influence of the diesel exhaust purification on the carbon aerosol of the fossil fuel origin was not observed. Fossil fuel origin carbon was understood to consist of EC as the main component. However, the contribution of organic carbon (OC) increased. Subsequently, the effect of diesel exhaust purification is difficult to determine.

Keywords: elemental carbon, organic carbon, carbon profile, isotropic carbon analysis, source contribution, fossil fuels, biomass combustion.

\section{Introduction}

The Japanese Ministry of Environment (MOE) promulgated the air quality standard of $\mathrm{PM}_{2.5}$ on September 2009. In the MOE report of 2010 fiscal year [1], an achievement ratio of $\mathrm{PM}_{2.5}$ air quality standard obtained at ambient monitoring sites was $32.4 \%$ and that of vehicle emission monitoring sites was $8.3 \%$. The annual average concentration of $\mathrm{PM}_{2.5}$ in remote areas with very little anthropogenic emission have values close to the air quality standard. Subsequently, it is difficult to achieve the $\mathrm{PM}_{2.5}$ standard in urban areas. In order to decrease $\mathrm{PM}_{2.5}$ concentrations and to understand the source contribution, chemical composition analysis was started to be performed at each local government site.

Vehicle emissions were major contributors of particulate matter (PM) [2]. However, with recent advances in emission reduction technology, the elemental carbon (EC) concentration that was representative of the primary particle in $\mathrm{PM}_{2.5}$ decreased in Tokyo noticeably. Figure 1 shows EC and organic carbon (OC) concentration trends for fine PM $\left(\mathrm{PM}_{2.1}\right)$ [3]. In recent years, while the diesel vehicle emissions predicted value was reduced, the EC concentration did not exhibit a concentration reduction commensurate with reduced emissions in Tokyo [4]. Therefore, it is necessary to review the origin of carbon emissions.

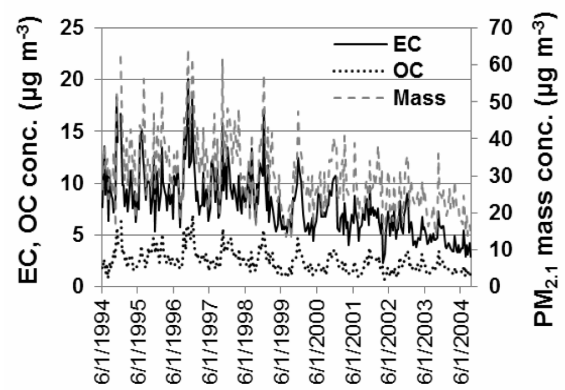

Figure 1: $\quad$ Concentration trend in $\mathrm{PM}_{2.1}$ observed at Tokyo, Japan. 
The goal of this study was to quantify the source contribution of EC and OC in the Tokyo metropolitan and suburban areas and around remote areas. Carbonaceous aerosol involves many carbonaceous compositions and changes with photochemical oxidation. Its source contribution and ambient behaviour is not well known [5]. Secondary organic aerosols (SOA) concentration prediction using an air quality simulation model has results which are less than observed results in many cases [6]. Research of undetected emission sources, such as VOC of from biomass origin (BVOC), has started [7].

To evaluate the effective improvement in $\mathrm{PM}_{2.5}$ concentration, the Ministry of Economy, Trade and Industry started the JATOP (Japanese Auto-Oil program) in 2007 to investigate the influence motor vehicle emissions have on ambient PM. During this program, two intentional observation campaigns were conducted in summer of 2008 and in winter of 2009. From aircraft measurement during the summer campaign, particle growth rate mostly from SOA was reported at an inland in the south Kanto area including Tokyo [8]. This study focused on the characteristics of carbonaceous aerosol and its emission source by using observed results from both campaigns.

\section{Observation}

\subsection{Method}

Four air monitoring sites were placed along the route of pollutants transfered by sea-land breeze [9] starting from "Urayasu" site of Tokyo Bay to "Kisai" site which was $60 \mathrm{~km}$ northwest from Urayasu and in the rural area in the south Kanto region. Sites "Kudan" and "Saitama" were placed in an areas representative of downtown Tokyo and the suburban Tokyo area, respectively. While having observed an air quality change inland from the Tokyo Bay at the four sites, change of east and west was studied at the National Institute for Environmental Study "NIES" site and the Tokyo Metropolitan University "TMU" site. The "Yoyogi" site was located in a large park $\left(0.54 \mathrm{~km}^{2}\right)$ in central Tokyo. This site is $4 \mathrm{~km}$ from the Kudan site, and was chosen to investigate the influence of vegetation. The summer observation was conducted from July 28 to August 11, 2008. The winter observation was conducted from November 23 to December 9, 2009. Observations during winter at NIES, TMU, and Yoyogi site were not used. In other words, observations were made only at the four main sites, i.e. Urayasu, Kudan, Saitama, and Kisai.

The observation methods are summarized in Table 1. Gas pollutants and weather observations were also conducted for $\mathrm{PM}_{2.5}$ reference data. $\mathrm{PM}_{2.5}$ was sampled starting at 9:00 and continued for 24 hours. The sampled filters were preserved in frozen storage immediately. Using a portion of the sampled filters, carbon components were analyzed using the Carbon Analyzer with the ThermalOptical-Reflectance Analysis (IMPROVE) method. In addition, levoglucosan analysis was performed using the same filters. Filter blanks and travel blanks were analysed for each $\mathrm{PM}_{2.5}$ filter samples, and the concentration estimation was adjusted accordingly. 
Table 1: $\quad$ Summary of ambient measurements.

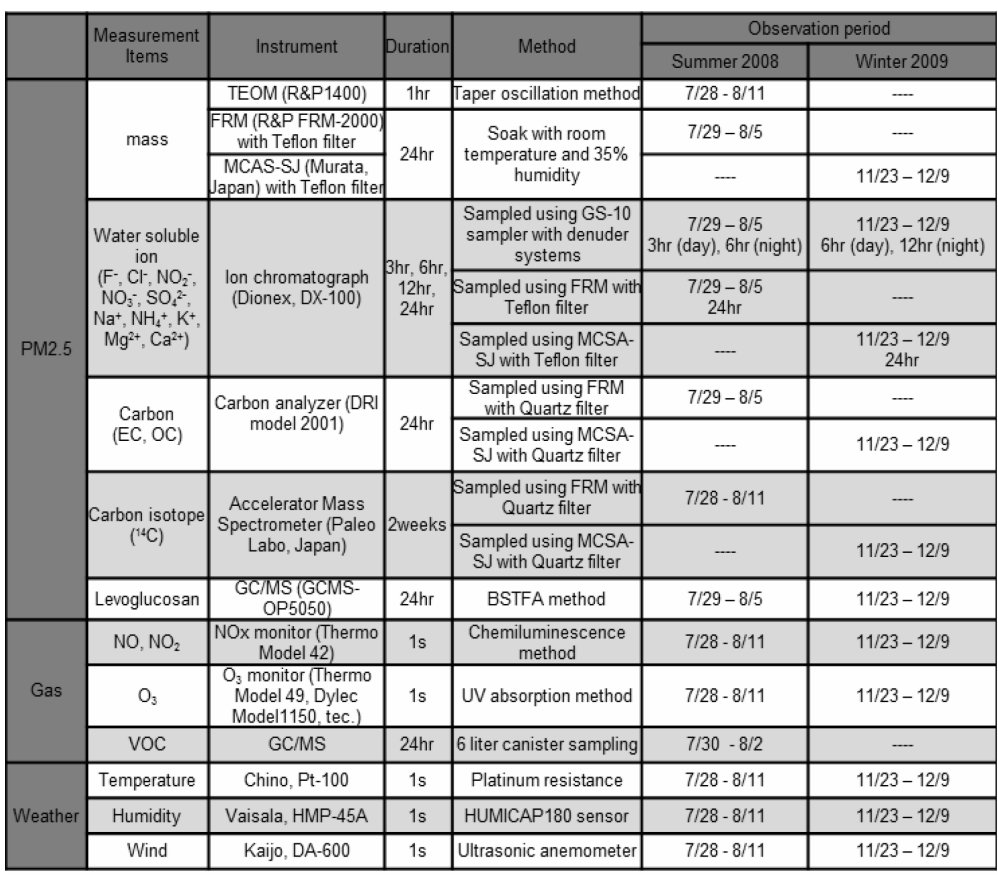

\subsection{Air pollution condition}

The mass concentration of the suspended particle matter (SPM) which is equivalent to $\mathrm{PM}_{7}$ is measured at more than 200 monitoring sites in the southern Kanto region by local governments. Figure 2 was based on SPM and wind data of these sites. Figure 2(a) and 2(c) show the spatial distribution of SPM concentration in summer and winter. In summer, a southern wind is prevailing

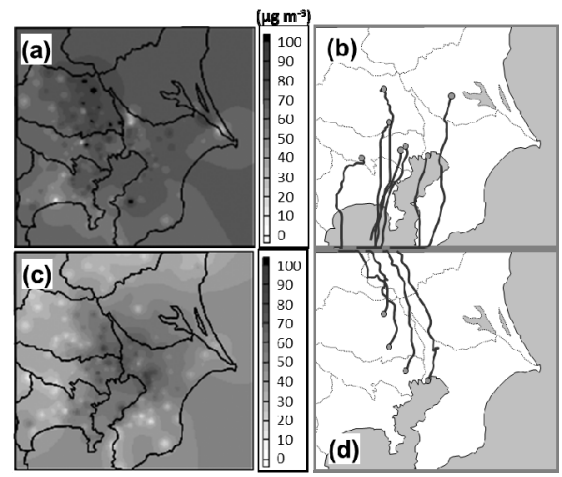

Figure 2: $\quad$ SPM spatial distribution ((a) and (c)) and pollutant trajectories ((b) and (d)). 
and anthropogenic pollutants, mostly emitted from the surrounding Tokyo Bay area are transported to the northern area. Figure 2(b) represents pollutant trajectories usually observed in summer. On the other hand, northern wind prevails in winter as shown in Figure 2(d), and the pollutants tend to be transported toward the south. Since there are many agricultural areas and few industrial facilities in the north compared with south area, overall PM concentration was lower in the winter than the summer.

\section{Analysis}

\subsection{Regional differences in carbon components}

The carbonaceous aerosol characterization was conducted using the IMPROVE thermal/optical reflectance protocol $[10,11]$ by using a Thermal/Optical Carbon Analyser, DRI Model 2001. In the carbon analyser, concentrations for four types of $\mathrm{OC}$ (from $\mathrm{OC} 1$ to $\mathrm{OC} 4$ ) were obtained by volatilization temperature (from $120^{\circ} \mathrm{C}$ to $550^{\circ} \mathrm{C}$ ), and three types of $\mathrm{EC}$ (from EC1 to EC3) were obtained (from $550^{\circ} \mathrm{C}$ to $800^{\circ} \mathrm{C}$ ), under an oxidized condition. In this observation, the concentration of $\mathrm{OC} 1$ was below the limit of detection in both seasons. Pyr-OC is a portion of the volatilizable carbon chars in the absence of oxygen, and this was measured using the reflected laser light as the filter darkens. After $\mathrm{O}_{2}$ was added, the original EC and pyrolized char evolved and the filter color lightens as detected by increasing reflectance. The carbon that evolves in the oxidizing atmosphere until the reflected light achieves its initial value is termed pyrolyzed organic carbon (Pyr-OC). Pyr-OC is mainly included in the organic carbon which receives the photochemical oxidation reaction. Char-EC is defined by [EC1]-[Pry-OC], and according to Han et al. [12], it is mostly contained in the combustion product of biomass or coal. On the other hand, Soot-EC is defined by $[E C 2]+[E C 3]$ and is mostly contained in combustion soot of n-hexane. Therefore, Char-EC exhibits the possibility of including biomass combustion as an emission source and Soot-EC has the possibility of including industrial sources such as diesel combustion as an emission source.

Carbonaceous concentrations in winter were higher than summer concentrations for all components except for EC2 and OC2 in Saitama and SootEC in all sites. Especially OC2 showed a tendency for high concentrations further inland. Correlation of OC2/Total Carbon (TC) with ozone concentration and sulfate/PM mass (composition ratio of sulfate) were comparatively high (correlation coefficients $r$ were 0.79 and 0.89 , respectively), and since a positive correlation with wind velocity was seen $(r=0.71)$, OC2 can be considered to possibility be from exhaust emissions of industrial origin which formed organic carbon in response to a photochemical reaction in the atmosphere. Pyr-OC showed the same tendency.

The tendency of high Soot-EC concentration in summer had little regional difference. High temperature combustion sources, such as power generators and industrial boilers, were located in a southern area, and a southern summer wind transported the soot to the entire south Kanto region. Since Soot-EC is a 
chemically stable substance, it is thought to have contributed to uniform distribution over the region. Soot-EC/TC showed negative correlation $(r=-0.73)$ with levoglucosan/mass, and the possibility of the biomass combustion origin was low. Furthermore, Soot-EC/TC showed positive correlation $(r=0.89)$ with sulfate/mass, and suggested the possibility of having an industrial origin.

Additionally, Char-EC was high during the winter campaign. Considering the north wind was predominant, it implies there were emission sources in the north. This suggests the possibility of the presence of biomass combustion in an agricultural area located in the north. The levoglucosan is one of the indices of biomass combustion, and its content in particles is shown in Fig. 3 for each observation site. The tendency of high Char-EC concentration was observed in the city suburbs and the agricultural area of northern area, such as Saitama and Kisai. However, levoglucosan is an unstable substance, so, the correlation with the Char-EC was low $(r=0.52)$. Additionally, the correlation of Char-EC/TC with nitric oxide (NO) was comparatively high $(r=0.84)$, there was a negative correlation with wind velocity $(r=-0.78)$ and there was a positive correlation with Chloride ion $\left(\mathrm{Cl}^{-}\right)$/mass which is an indices of garbage combustion involving biomass $(r=0.75)$. Therefore, these were considered to be characteristics of the various local low-temperature combustion emission originators which were different from industrial high temperature combustion emission originators.

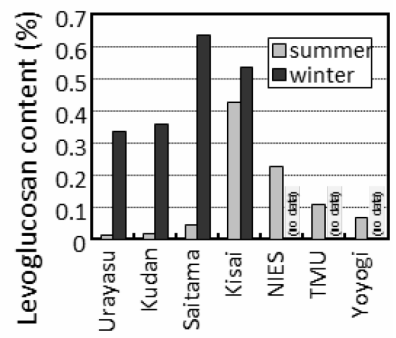

Figure 3: $\quad$ Comparisons of levoglucosan contents in $\mathrm{PM}_{2.5}$.

When the levoglucosan contents involving particles as an indicator of bioorigin, as shown in Figure 4a, much of the Char-EC/TC observed in the winter was considered to be bio-origin. Here, Bio-origin of Char-EC was obtained from the correlation between levoglucosan and Char-EC, and the remaining portion was defined as non-Bio-origin. However, during the summer much of CharEC/TC had non-bio-origin. Soot-EC/TC had almost same content (6\%) for sites in the winter in Figure 4b, it is theorized that a uniform emission source such as diesel exhaust contributed to the entire northern area. The value of Soot-EC/TC had some variation during the summer over the different areas. This value was considered to include contributions of neighbouring industrial emission. In particular, Urayasu showed high Soot-EC/TC, and marine vessel emissions can be considered to be sources. 

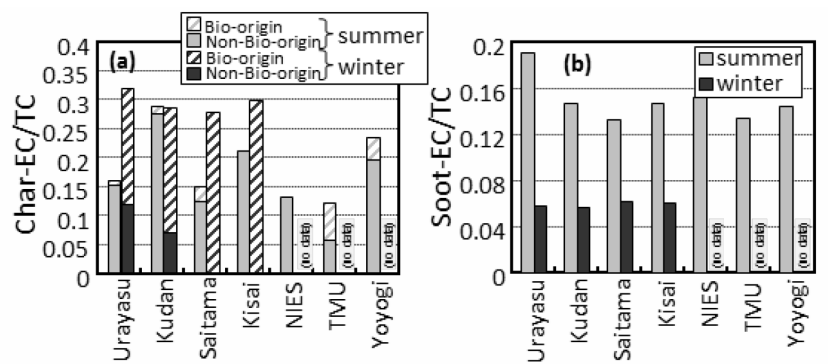

Figure 4: $\quad$ Comparisons of (a) Char-EC and (b) Soot-EC in total carbon (TC).

\subsection{Regional differences in isotopic carbon concentration}

The percent modern carbon (pMC) which is an index of biomass origin, is estimated on the basis of the ${ }^{14} \mathrm{C}$ concentration in 1950 as reference value (pMC $=100 \%, \Delta \Delta^{14} \mathrm{C}=0 \%$ ), and corrected the isotope fractionation effect by normalizing the sample $\delta^{13} \mathrm{C}$ value to $-25.0 \%$. As a result of the isotopic carbon analysis using total carbon, pMC was obtained for each observation sites. As shown in Fig. 5, pMC of TC at Kudan had the lowest result (29\%), and the highest result was at NIES (47\%). As expected, results showed a high biomass

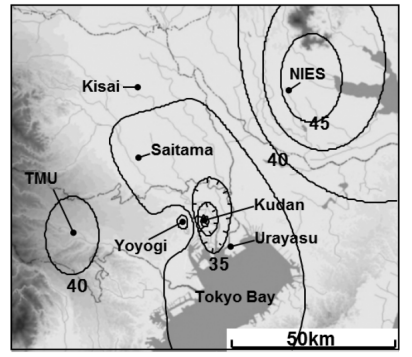

Figure 5: Spatial distribution of Figure 6: pMC in summer 2008.

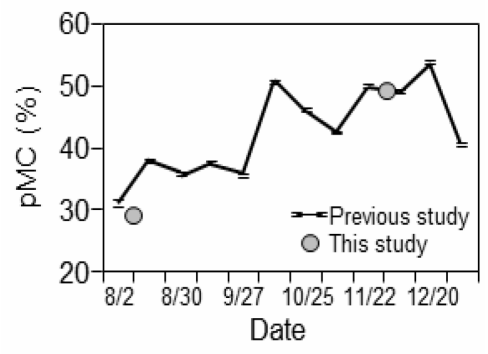

Seasonal change in pMC and comparisons observed at Kudan.

contribution in the suburbs. Additionally, it became apparent that biomass emission contributed to nearly $29 \%$ of TC in central Tokyo. Possible biomass combustion sources in central Tokyo are: cooking smoke, tobacco smoke, and garbage incineration (private communication with researchers of Tokyo government). At the Yoyogi site, which is close to the Kudan site, it should be noted that the pMC value was $12 \%$ higher than Kudan. Since Yoyogi Park is one of the largest metropolitan parks in central Tokyo, it is improbable large-scale biomass combustion occurred there. Organic carbon from biogenic VOC (BVOC) origin without combustion is considered to be one of the sources.

In the 2009 winter campaign, sampled filters were cut in half. One half of the filters were analyzed with a similar method as the summer samples for isotopic carbon analysis as TC. The other half of the filter analyzed for OC and Pyr-OC 
in a Carbon Analyser, then cooled immediately and an isotopic analysis as an EC sample was conducted. The higher pMC was observed in the suburbs compared to central Tokyo, and in winter compared to summer. Since the north wind was present in the winter, it supported the hypothesis of biomass contributions being transported from the northern area. The tendency where pMC in Kudan during the winter increased to $48 \%$ from $29 \%$ in the summer agreed with a previous study observed in 2004 [13], as shown in Figure 6. Fossil fuel emission contribution at the four main sites on average was $61 \%$ and $49 \%$ in the summer and winter, respectively. These values for the Japan rural area are about $20 \%$ higher than the Europe rural background [14].

Table 2: $\quad$ Summary of pMC involved in carbon components.

\begin{tabular}{|l|c|c|c|c|c|c|c|c|c|}
\hline & pMC & Urayasu & Kudan & Saitama & Kisai & NIES & TMU & Yoyogi & average \\
\hline Summer 2008 & TC & $37.32 \pm 0.14$ & $29.14 \pm 0.12$ & $35.48 \pm 0.13$ & $38.79 \pm 0.15$ & $46.97 \pm 0.15$ & $41.01 \perp 0.16$ & $41.07 \pm 0.14$ & 38.5 \\
\hline & TC & $46.73 \pm 0.16$ & $48.15 \pm 0.17$ & $49.37 \pm 0.18$ & $59.32 \pm 0.16$ & & & & 50.9 \\
\hline \multirow{2}{*}{ Winter 2009 } & EC & $35.02 \pm 0.16$ & $35.23 \pm 0.12$ & $38.23 \pm 0.13$ & $45.54 \pm 0.16$ & & & & 38.5 \\
\hline & OC & 53.60 & 54.99 & 55.21 & 66.72 & & & \\
\hline
\end{tabular}

Table 2 shows pMC obtained by analysis based on TC and $\mathrm{EC}$ and the estimated value of $\mathrm{pMC}$ contained in $\mathrm{OC}\left(\mathrm{pMC}_{\mathrm{OC}}\right)$ as obtained by Equation (1):

$$
\mathrm{pMC}_{\mathrm{OC}}=[\mathrm{EC}] /[\mathrm{OC}] \times\left(\mathrm{pMC}_{\mathrm{TC}}-\mathrm{pMC}_{\mathrm{EC}}\right)+\mathrm{pMC}_{\mathrm{TC}}
$$

where $\mathrm{pMC}_{\mathrm{TC}}$ and $\mathrm{pMC}_{\mathrm{EC}}$ means $\mathrm{pMC}$ based on $\mathrm{TC}$ and $\mathrm{EC}$, respectively. Furthermore, as restriction conditions, Equations 2 and 3 have been established:

$$
\begin{gathered}
{[\mathrm{TC}]=[\mathrm{EC}]+[\mathrm{OC}]} \\
{[\mathrm{BTC}]=[\mathrm{BEC}]+[\mathrm{BOC}]}
\end{gathered}
$$

where $[\mathrm{BTC}],[\mathrm{BEC}]$, and $[\mathrm{BOC}]$ means biomass origin concentration of $\mathrm{TC}$, EC, and OC, respectively. From results shown in Table 2, approximately 58\% of carbonaceous aerosols originated as $\mathrm{BOC}$, and contribution of $\mathrm{BOC}$ was higher than BEC even in the winter season. Since it was expected that large quantities of VOCs with bio-origin evaporate in summer compared to the winter, increased BOC contribution was also expected in summer. It is hypothesized that the high pMC value at the Yoyogi site had a high BOC contribution.

Using the pMC obtained in Table 2, the concentration was estimated according to the origin of carbonaceous aerosol, and is shown in Figure 7. As shown in Figure 7(a), carbonaceous aerosol of fossil fuel origin (FTC) exceeded the biomass origin (BTC) and emissions of industrial areas near Tokyo Bay increased FTC concentration of the neighborhood site. The FTC concentration of Urayasu was low $\left(1.1 \mu \mathrm{g} \mathrm{m}^{-3}\right)$, since emissions are dispersed to Tokyo Bay. However, the ratio of FTC contained in TC (FTC/TC) became the highest $(63 \%)$ of all sites same as Soot-EC/TC shown in Figure 4(b). 

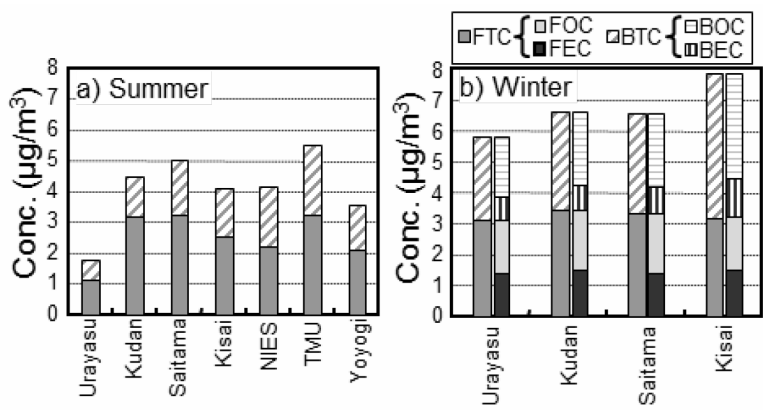

Figure 7: Carbonaceous aerosol concentration and their estimated origin.

Winter results are shown in Figure 7(b). This had similar FTC concentration results of about $3 \mu \mathrm{g} \mathrm{m}^{-3}$ for all observation sites. EC from fossil fuel origin (FEC) involves Soot-EC. However, Soot-EC showed a different tendency than the inland high concentrations. This implies that some portion of Char-EC was involved in FEC. In the future, it will be necessary to inspect FEC content included in Char-EC. Furthermore, it was hypothesized that the majority of FTC was in a state of EC, but it became clear that OC contribution to FTC was large (average 56\%).

The biomass contribution measured for this study does not show a significant difference between the measured results in 2004. Diesel exhaust purification on the carbon aerosol of the fossil fuel origin was not seen. Fossil fuel origin carbon was understood to be EC was main contributor. However, the contribution of organic carbon (OC) was found to be larger than the fossil fuel contribution. For this reason, the effect of diesel exhaust purification affect was difficult to determine.

BTC showed good correlation with levoglucosan. However, as shown in Figure 8 , the approximate line offset at BTC was $0.3 \mu \mathrm{g} \mathrm{m}^{-3}$. This could be due to two processes. The first is a process in which BTC stays in the air for a long period as a background component, until the time when levoglucosan decomposes and disappears. The second is a process in which BTC (BOC) is generated from a non-combustion origin. The majority of BTC was expected to be in the form of OC (average 73\%), and the concentration of BOC showed increased concentrations inland. Reasons suggested for this were an

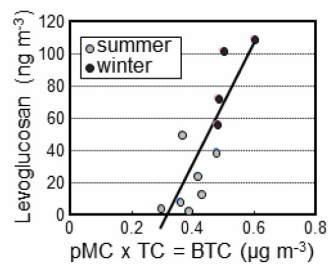

Figure 8: Relationship with BTC and levoglucosan concentration. 
accumulation of BVOC in inland areas and a photochemical change to OCoccured. Weber et al. [15] stated that $70-80 \%$ of carbon in water-soluble OC was from biogenic origin in Atlanta in summer as determined by radiocarbon measurements. Additionally, Szidat et al. [16] concluded there is a $59-80 \%$ biogenic contribution to OC particle formation found in daytime collected samples. Therefore, further investigation regarding the bio-origin of $\mathrm{OC}$ as a component of $\mathrm{PM}_{2.5}$ formation is required.

Biomass origin of EC (BEC) showed similar concentrations at all sites except in Kisai. In Japan prior to 2009, since the use of biofuels for automobile was minimal, BEC were considered mainly due to other combustion sources such as daily tobacco and cooking smoke. Moreover, biomass combustion on an industrial scale such as garbage incineration may have occurred in Kisai.

Study of carbonaceous aerosol behavior using carbon isotope is in its infancy. In order to clarify the origin of carbonaceous aerosol, seasonal or daily observation with improved measurement accuracy is needed, and the time and spatial variation of the carbonaceous aerosols of fossil fuel origin and biomass origin should be understood.

\section{Conclusions}

Observation of $\mathrm{PM}_{2.5}$ was conducted in south Kanto, in the summer of 2008, and the winter of 2009. The characteristics of carbonaceous aerosol were obtained using carbon profile analysis and carbon isotope analysis.

1. OC2 showed a correlation with ozone concentration and wind velocity. This suggests OC2 is formed through photochemical oxidization. In summer, due to southern wind transportation, high OC2 concentration was measured in the northern area of the south Kanto region.

2. Soot-EC is a substance from fossil fuel origin which does not contain biomass combustion matter, and since it is stable, there was no observed difference by site and a uniform concentration was observed in winter. Due to the exhaust influence of the industrial facilities around Tokyo Bay, neighbourhood observation site showed high concentration in summer. Among the four observation sites, Urayasu had the highest the ratio of Soot-EC in total carbon, the influence of marine vessel emissions was considered to be the source.

3. Char-EC had origins from industrial combustion including diesel combustion and biomass combustion. The industrial combustion contribution was determined to be larger in summer than biomass combustion contribution, while the reverse was determined for the winter, i.e. larger biomass combustion in the winter than industrial combustion contribution.

4. It became clear from the carbon isotope analysis using ${ }^{14} \mathrm{C}$ that the carbon from biomass origin comprised $29 \%$ of total carbon in the summer, and $48 \%$ in the winter even at Kudan in the central Tokyo. The tendency for biomass contribution increased about $10 \%$ in the suburbs or the northern remote area. 
5. Particle concentration with fossil fuel emission origin (FTC) in the winter was about $3 \mu \mathrm{g} \mathrm{m}^{-3}$ and a regional difference was not found. Approximately $56 \%$ of FTC was fossil fuel OC. $73 \%$ of the particles of biomass origin (BTC) observed in the winter were BOC.

6. The diesel vehicle exhaust purification does not show a clear difference in pMC observed at a central Tokyo in comparison with a previous study in 2004. Fossil fuel origin carbon was understood that EC was main subject, however, the contribution of organic carbon (OC) was found bigger. For this reason, it is thought that the effect of diesel exhaust purification becomes difficult to see its effect.

Carbon isotope analysis is an effective technique and needs to be used in the future to investigate changes for every season or time period. Furthermore, the carbon isotope analysis in conjunction with carbon profile is expected to give more detailed information about source emissions by investigating the $\mathrm{pMC}$ of each carbon component of OC and EC.

\section{Acknowledgement}

This research was commissioned by the Ministry of Economy, Trade and Industry, and as part of a collaborative research program between auto and oil industries called Japan Auto-Oil Program (JATOP) run by Japan Petroleum Energy Center.

\section{References}

[1] http://www.env.go.jp/press/press.php?serial=14869.

[2] Chow, J.C., Watson, J.G., Review of PM2.5 and PM10 apportionment for fossil fuel combustion and other sources by the chemical mass balance receptor model. Energy \& Fuels 16 (2), 222-260, 2002.

[3] Minoura, H., Takahashi, K., Chow, J.C., Watson, J.G., Multi-year trend in fine and coarse particle mass, carbon, and ions in downtown Tokyo, Japan. Atmospheric Environment 40, 2478-2487, 2006.

[4] Minoura, H., Takahashi, K., Chow, J.C., Watson, J.G., Vehicle emission regulation and air quality improvement in atmospheric aerosols in downtown Tokyo. 4th IASME/WSEAS International Conference on Energy, Environment, Ecosystems and Sustainable Development. ISBN: 978-960-6766-71-8, 353-359, 2008.

[5] Lelieveld, J., Butler, T. M., Crowley, J. N., Dillon, T. J., Fischer, H., Ganzeveld, L., Harder, H., Lawrence, M. G., Martinez, M., Taraborrelli, D., Williams, J., Atmospheric oxidation capacity sustained by a tropical forest. Nature 452, 737-740, 2008.

[6] Hodzic, A., Jimenz, J.L., Madronich, S., Aiken, A.C., Bessagnet, B., Curci, G., Fast, J., Lamarque, J.-F., Onasch, T.B., Roux, G., Schauer, J.J., Stone, E.A., Ulbrich, I.M., Modeling organic aerosols during MILAGRO: 
importance of biogenic secondary organic aerosols. Atmospheric Chemistry and Physics 9, 6949-6982, 2009.

[7] Kiendler-Scharr, A., Wildt, J., Dal Maso, M., Hohaus, T., Kleist, E., Mentel, T. F., Tillmann, R., Uerlings, R., Schurr, U., Wahner, A., New particle formation in forests inhibited by isoprene emissions. Nature, 461, 381-384, 2009.

[8] Minoura, H., Shimo, N., Spatial distribution of particle number concentration and its volume change in the planetary boundary layer over Tokyo and its suburban areas. Atmospheric Environment 45, 4603-4610, 2011.

[9] Yoshikado, H., Tsubaki, T., Sasaki, K., Feasibility of a Method Simulating Long-term Average Concentration of Pollutants Based on a Mesoscale Meteorological Model: (II) Application to Assessment of High-level Local Ozone. Japan Society for Atmospheric Environment, 41, 15-26, 2006.

[10] Chow, J.C., Watson, J.G., Pritchett, L.C., Pierson, W.R., Frazier, C.A., Purcell, R.G., The DRI thermal/optical reflectance carbon analysis system: description, evaluation and applications in U.S. air quality studies. Atmospheric Environment 27, 1185-1201, 1993.

[11] Chow, J.C., Watson, J.G., Chen, L.-W.A., Paredes-Miranda, G., Chang, M.C.O., Trimble, D., Fung, K., Zhang, H., Yu, J.Z. Refining temperature measures in thermal/optical carbon analysis. Atmospheric Chemistry and Physics 5, 2961-2972, 2005.

[12] Han, Y., Cao, J., Chow, J.C., Watson, J.G., An, Z., Jin, Z., Fung, K., Liu, S. Evaluation of the thermal/optical reflectance method for discrimination between char- and soot-EC. Chemosphere 69, 569-574 2007.

[13] Takahashi, K., Hirabayashi, M., Tanabe, K., Shibata, Y., Nishikawa, M., Sakamoto, K. Radiocarbon Content in Urban Atmospheric Aerosols. Water Air and Soil Pollution 185, 305-310, 2007.

[14] Gilardoni, S., Vignati, E., Cavalli, F., Putaud, J.P., Larsen, B.R., Karl, M., Stenström, K., Genberg, J., Henne, S., Dentenr, F. Better constraints on source of carbonaceous aerosols using a combined $14 \mathrm{C}$ - macro tracer analysis in a European rural background site. Atmospheric Chemistry and Physics 11, 5685-5700, 2011.

[15] Weber, R.J., Sullivan, A.P., Peltier, R.E., Russell, A., Yan, B., Zheng, M., Gouw, J., Warneke, C., Brock, C., Holloway, J.S., Atlas, E.L., Edgerton, E. A study of secondary organic aerosol formation in the anthropogenicinfluenced southeastern United States. Journal of Geophysical Research 112, D13302. doi:10.1029/2007JD008408, 2007.

[16] Szidat, S., Jenk, T.M., Gäggeler, H.W., Synal, H.-A., Fisseha, R., Baltensperger, U., Kalberer, M., Samburova, V., Reimann, S., KasperGiebl, A., Hajdas, I. Radiocabon $\left({ }^{14} \mathrm{C}\right)$-deduced biogenic and anthropogenic contribution to organic carbon (OC) of urban aerosols from Zürich, Switzerland. Atmospheric Environment 38, 4035-4044, 2004. 